\title{
Relapse of visceral leishmaniasis in an HIV-infected patient successfully treated with a combination of miltefosine and amphotericin B
}

\author{
Shauna McQuarrie $M D^{1}$, Ken Kasper MD², ${ }^{1,2}$ Dana C Moffatt MD², Daniel Marko MD³, Yoav Keynan MD PhD ${ }^{1,2}$
}

S McQuarrie, K Kasper, DC Moffatt, D Marko, Y Keynan. Relapse of visceral leishmaniasis in a HIV-infected patient successfully treated with a combination of miltefosine and amphotericin B. Can J Infect Dis Med Microbiol 2015;26(6):325-329.

The present report documents a 49-year-old HIV-infected man receiving antiretroviral therapy with a suboptimal immune response and a CD4 count of 95 cells $/ \mathrm{mm}^{3}$, despite virological suppression. Investigation of bone marrow was conducted and yielded a diagnosis of visceral leishmaniasis. The clinical course was complicated by gastrointestinal involvment and relapse occurred after amphotericin B therapy. With the addition of miltefosine, the patient no longer presented with bone marrow amastigotes, and displayed an increased CD4 count and negative Leishmania polymerase chain reaction results. The present case highlights atypical presentation of visceral leishmaniasis, including poor immune reconstitution and gastrointestinal involvement. The high likelihood of relapse and response to combination therapy are illustrated.

Key Words: Combination therapy; HIV visceral leishmania coinfection; Miltefosine; Visceral leishmaniasis

49-year-old HIV-infected patient receiving antiretroviral therapy $\mathrm{I}_{\text {who was virologically suppressed, presented with a suboptimal }}$ immune response and a CD4 count of 95 cells $/ \mathrm{mm}^{3}$.

The patient was an Ethiopian man who immigrated to Canada. After spending the first two decades of his life in northern Ethiopia near Mekele and Gonder, which are near the Sudanese border, he moved to Addis Ababa and, later, the eastern region of Ogaden. Leaving Kenya in his mid-thirties, he lived in a refugee camp in Kenya for 13 years.

Known to be HIV positive since 2006, he entered care with the Manitoba HIV program on arrival to Canada four years later. His highly active antiretroviral therapy (HAART) regimen, which had been initiated at diagnosis, consisted of twice daily stavudine, lamivudine and nevirapine; he was not receiving any opportunistic infection prophylaxis at the time of his arrival into care in Canada.

Previous medical diagnoses included asthma, gastroesophageal reflux disease and malaria. He had partially completed a course of therapy for malaria shortly before arrival to Canada, and repeat testing was negative. Gastrointestinal symptoms had been present for three years and consisted of retrosternal burning, and intermittent central chest and epigastric pain. This pain radiated to his back, and worsened with eating or with ingesting medications. He experienced two episodes of hematemesis but no melena.

Initial examination revealed a thin man (body mass index $16.1 \mathrm{~kg} / \mathrm{m}^{2}$ ) with scarring on his chest wall consistent with a past episode of herpes zoster. Abdominal examination revealed a palpable splenic tip. No

\author{
La rechute d'une leishmaniose viscérale chez un \\ patient infecté par le VIH traité au moyen d'une \\ association de miltéfosine et d'amphotéricine B
}

Le présent rapport rend compte du cas d'un homme de 49 ans atteint du VIH sous antirétroviraux dont la réponse immunitaire était sousoptimale et dont la numération de CD4 était de 95 cellules $/ \mathrm{mm}^{3}$, malgré une suppression virologique. L'examen de la moelle osseuse a confirmé un diagnostic de leishmaniose viscérale. L'évolution clinique de la maladie a été compliquée par une atteinte gastro-intestinale, et le patient a fait une rechute après un traitement à l'amphotéricine B. Après l'ajout de miltéfosine, le patient n'avait plus d'amastigotes de la moelle osseuse, présentait une augmentation de la numération de CD4 et des résultats négatifs de Leishmania à la réaction en chaîne par polymérase. Le présent cas fait ressortir la présentation atypique de cette leishmaniose viscérale, y compris la mauvaise reconstitution immunitaire et l'atteinte gastro-intestinale. La forte probabilité de rechute et de réponse à une thérapie combinée est exposée. lymphadenopathy could be discerned, and the remainder of his physical examination was unremarkable.

During the course of his initial assessment, his CD4 count was 95 cells $/ \mathrm{mm}^{3}$, with a discordant CD4 percentage of $17 \%$ and a suppressed viral load. Sulfamethoxazole-trimethoprim was subsequently started for Pneumocystis jirovecii pneumonia prophylaxis. Due to the patient's symptoms from stavudine and its long-term side effects, his antiretroviral regimen was changed to tenofovir, emtricitabine and nevirapine.

There were other notable abnormalities from his initial laboratory report, including an elevated thyroid stimulating hormone level and pancytopenia (white blood cells [WBCs] $2.67 \times 10^{9} / \mathrm{L}$, neutrophils $1.9 \times 10^{9}$, normocytic anemia with a hemoglobin of $81 \mathrm{~g} / \mathrm{L}$, platelets initially normal but when repeated were low $\left.\left[121 \times 10^{9}\right]\right)$. Thyroid replacement was initiated and additional laboratory testing was performed to investigate the etiology of the pancytopenia.

No reticulocytosis was present, rouleaux formation was detected, $\mathrm{B}_{12}$ was normal, ferritin was slightly elevated $(280 \mu \mathrm{g} / \mathrm{L})$, and he had low serum iron and total iron-binding capacity. Liver enzyme levels, including lactate dehydrogenase, bilirubin, lipase and creatinine were all within normal limits. There was no evidence of hemolysis. Hemoglobin S screen was positive, and hemoglobin electrophoresis determined no hemoglobin disorders .

Splenomegaly was confirmed using ultrasound $(14.3 \mathrm{~cm}$ in length, which is considered to be mildly enlarged) and a bone marrow aspirate

\footnotetext{
${ }^{1}$ Manitoba HIV Program; ${ }^{2}$ Department of Internal Medicine, University of Manitoba; ${ }^{3}$ Diagnostic Services of Manitoba, Winnipeg, Manitoba Correspondence: Dr Yoav Keynan, Department of Internal Medicine, Medical Microbiology, Community Health Sciences, University of Manitoba, Winnipeg, Manitoba R3E OW3. Telephone 204-789-3296, e-mail keynany@yahoo.com
} 


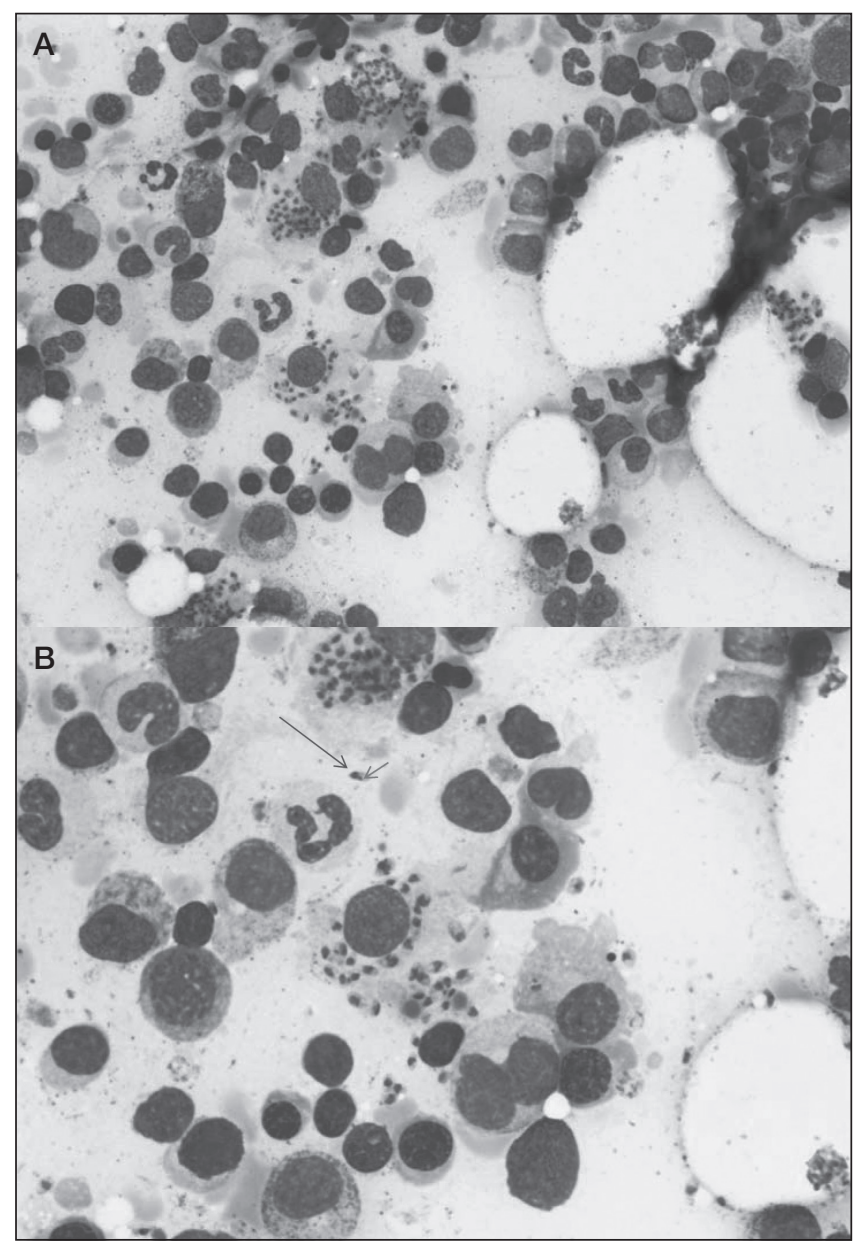

Figure 1) Giemsa stained bone marrow aspirate demonstrating intra- and extracellular amastigotes (A). Nucleus (long arrow) and a kinetoplast (short arrow) are apparent within amastigotes (B)

was proposed to clarify the etiology of his pancytopenia; however, the patient declined to undergo the procedure at that time.

Further laboratory tests performed to investigate his gastrointestinal symptoms revealed positive Helicobacter pylori serology for which he was treated with lansoprazole, amoxicillin and clarithromycin. Despite completing the course of therapy, his symptoms persisted and the patient was referred to gastroenterology for further evaluation.

Before being observed, he was hospitalized with bilateral pleural effusions and treated presumptively for tuberculosis (TB) due to his risk factors for $\mathrm{TB}$ acquisition and activation (he was from an area where TB is endemic and he was significantly immunocompromised), and the presence of a lymphocytic effusion with a tree-in-bud appearance of his left lower lobe was revealed by computed tomography scan. The pleural fluid was both smear negative and culture negative for TB. He improved clinically after induction therapy with rifampin/isoniazid/ pyrazinamide/ethambutol. Ethambutol was switched to moxifloxacin due to ocular symptoms, and induction therapy was followed by isoniazid and rifampin for a subsequent six-month period.

The patient experienced ongoing abdominal pain, fullness, intermittent diarrhea and constipation, as well as nausea and vomiting. A gastroscopy was performed revealing candidal esophagitis and chronic gastritis, including gastric antral and proximal duodenal biopsies illustrating numerous leishmanial parasites. The patient also consented to undergo a bone marrow aspirate to investigate his persistent pancytopenia. Numerous extracellular and intracellular parasites consistent with Leishmania amastigotes were observed, and he subsequently underwent treatment with outpatient intravenous (IV) liposomal amphotericin B $4 \mathrm{mg} / \mathrm{kg} /$ day for 10 doses, for a total dose of $40 \mathrm{mg} / \mathrm{kg}(1)$.

Initially, his gastrointestinal symptoms improved after treatment. No direct follow-up testing was performed; however, a subsequent ultrasound revealed a reduction of his splenomegaly and his hematological parameters improved (hemoglobin increased from $87 \mathrm{~g} / \mathrm{L}$ to $101 \mathrm{~g} / \mathrm{L}$, WBC count from $2.4 \times 10^{9}$ to $4.3 \times 10^{9}$, neutrophils from $1.48 \times 10^{9}$ to $3.5 \times 10^{9}$ and platelets from $99 \times 10^{9}$ to $187 \times 10^{9}$ ); however, he had no improvement of his CD4 count.

Unfortunately, over the subsequent nine months, he experienced recurrent gastrointestinal symptoms along with worsening of his hematological parameters.

A repeat bone marrow aspirate performed one year after his initial treatment confirmed the presence of leishmaniasis organisms (Figure 1). His CD4 count at the time was 104 cells $/ \mathrm{mm}^{3}$ (16\%) and his HIV viral load was undetectable.

The organism was confirmed to be Leishmania donovani, speciated using polymerase chain reaction (PCR).

His antiretroviral regimen was changed to include a protease inhibitor due to its potential for some direct and indirect antileishmanial activity based on in vitro data (2). His new antiretroviral regimen consisted of tenofovir, emtricitabine and darunavir boosted with ritonavir.

Before retreatment of the leishmaniasis, he experienced recurrent epigastric pain and odynophagia and, therefore, endoscopy was repeated. Esophagogastroduodenoscopy revealed candidal esophagitis, and biopsies from both the esophagus and duodenum were positive for leishmaniasis. The esophageal candidiasis was treated with oral fluconazole.

Treatment consisted of IV liposomal amphotericin B ( $5 \mathrm{mg} / \mathrm{kg} / \mathrm{dose})$ for six doses on alternating days (Monday/Wednesday/Friday), along with 28 days of oral miltefosine $100 \mathrm{mg}(2.5 \mathrm{mg} / \mathrm{kg})$. He experienced a transient rise in creatinine level, which resolved a few weeks after stopping the amphotericin $\mathrm{B}$.

The patient's epigastric pain improved post-treatment, his splenomegaly resolved and laboratory parameters improved (WBC increased from $2.6 \times 10^{9} / \mathrm{L}$ to $4.3 \times 10^{9} / \mathrm{L}$, neutrophils from $1.8 \times 10^{9}$ to $3.2 \times 10^{9}$, hemoglobin from $82 \mathrm{~g} / \mathrm{L}$ to $103 \mathrm{~g} / \mathrm{L}$ and platelets from $68 \times 10^{9}$ to $115 \times 10^{9}$ ) and his CD4 count rose from 93 cells $/ \mathrm{mm}^{3}$ to 158 cells $/ \mathrm{mm}^{3}$. Splenic aspiration was considered to confirm resolution of the infection; however, with the decrease in splenic size and clearance of infection from the bone marrow after therapy, it was decided that the procedure would not be performed at that time.

A follow-up bone marrow aspirate performed approximately six months post-treatment was free of amastigotes, bone marrow culture was negative for Leishmania, as was the aspirate leishmaniasis DNA PCR testing. Serum leishmaniasis DNA PCRs remained negative 15 months after treatment of his relapse, and his most recent CD4 count was 232 cells $/ \mathrm{mm}^{3}$ (20\%).

\section{DISCUSSION}

Leishmaniasis is a protozoal infection transmitted by the bite of female sandflies, with the majority (90\%) of cases being reported from India, Nepal, Bangladesh, Brazil and Sudan. In some regions, up to $30 \%$ of the population is asymptomatically infected (3).

Leishmaniasis has three main forms, cutaneous (the most common form), mucocutaneous and visceral (sometimes known as kala-azar). Visceral leishmaniasis (VL) is a disseminated form of the infection caused primarily by the species Leishmania donovani and Leishmania infantum, and occurs when the organism targets the reticuloendothelial system. Classic features of the disease include chronic fever, weight loss, pancytopenia and organomegaly; however, the majority of individuals with VL are asymptomatic. Our patient lacked the typical symptom of fever, and never developed the expected marked splenomegaly (maximal spleen length was $17.8 \mathrm{~cm}$ ).

Our patient's diagnosis was made using bone marrow biopsy. Interestingly, because of organism heterogeneity, serological testing for leishmaniasis varies in sensitivity depending on the test used, the individual's region of origin, and is further reduced in HIV coinfection (4). 
TABLE 1

Review of published reports of visceral leishmaniasis with gastrointestinal (GI) involvement

\begin{tabular}{|c|c|c|c|c|c|}
\hline $\begin{array}{l}\text { Author } \\
\text { (reference), year }\end{array}$ & $\begin{array}{l}\text { Symptoms of } \\
\text { GI involvement }\end{array}$ & $\begin{array}{l}\text { Patient's } \\
\text { country } \\
\text { of origin }\end{array}$ & $\begin{array}{l}\text { Site of GI } \\
\text { involvement }\end{array}$ & Treatment & Outcome \\
\hline \multicolumn{6}{|c|}{ McQuarrie et al (present case), 2015} \\
\hline 1 & $\begin{array}{l}\text { Abdominal pain, nausea, } \\
\text { vomiting, diarrhea }\end{array}$ & $\begin{array}{l}\text { Ethiopia, } \\
\text { Kenya }\end{array}$ & $\begin{array}{l}\text { Esophagus, gastric } \\
\text { antrum and proxi- } \\
\text { mal duodenum }\end{array}$ & $\begin{array}{l}\text { Liposomal amphotericin B; relapse } \\
\text { treated with liposomal amphotericin B } \\
\text { and miltefosine }\end{array}$ & $\begin{array}{l}\text { Responded with negative } \\
\text { leishmaniasis antigen } \\
\text { titres after second course } \\
\text { of treatment }\end{array}$ \\
\hline \multicolumn{6}{|l|}{ Diro et al (20), 2015} \\
\hline 1 & & Ethiopia & $\begin{array}{l}\text { Oral mucosa (1), } \\
\text { rectum (1) }\end{array}$ & Liposomal amphotericin B & \\
\hline 2 & $\begin{array}{l}\text { Fever, weight loss, abdominal } \\
\text { mass }\end{array}$ & Ethiopia & $\begin{array}{l}\text { Abdominal lymph } \\
\text { node }\end{array}$ & Sodium stibogluconate & Responded \\
\hline 3 & $\begin{array}{l}\text { Diarrhea, fever, vomiting, oral } \\
\text { lesions }\end{array}$ & Ethiopia & Oral mucosa & Liposomal amphotericin B & Died from septic shock \\
\hline 4 & $\begin{array}{l}\text { Anal bleeding, fever, weight } \\
\text { loss, rectal ulcer }\end{array}$ & Ethiopia & Rectal mucosa & Sodium stibogluconate & $\begin{array}{l}\text { Responded, persistent fecal } \\
\text { incontinence }\end{array}$ \\
\hline 5 & Painless nodular skin lesions & Ethiopia & Skin, spleen & Sodium stibogluconate & Responded \\
\hline \multicolumn{6}{|c|}{ Alonso et al (19), 1997} \\
\hline 1 & Diarrhea & $\begin{array}{l}\text { Spain } \\
\text { (travelled } \\
\text { to Mexico) }\end{array}$ & Duodenum & Pentavalent antimonials & $\begin{array}{l}\text { Persistent diarrhea and } \\
\text { Leishmania seen on follow } \\
\text { up duodenal biopsy }\end{array}$ \\
\hline 2 & $\begin{array}{l}\text { Diarrhea, fever, abdominal } \\
\text { pain, weight loss }\end{array}$ & Spain & Duodenum & $\mathrm{N}$-methylglutamine antimoniate & $\begin{array}{l}\text { Died, renal function } \\
\text { deteriorated }\end{array}$ \\
\hline \multicolumn{6}{|c|}{ Canet et al (21), 2003} \\
\hline 1 & Dysphagia & Spain & $\begin{array}{l}\text { Midesophageal } \\
\text { lesion }\end{array}$ & $\begin{array}{l}\text { Pentavalent antimony and oral } \\
\text { allopurinol; sodium stibogluconate } \\
\text { every } 2 \text { weeks thereafter }\end{array}$ & Responded \\
\hline \multicolumn{6}{|c|}{ Molaei et al (22), 2007} \\
\hline 1 & $\begin{array}{l}\text { Fever, abdominal pain, } \\
\text { vomiting, diarrhea, } \\
\text { weight loss, loss of appetite }\end{array}$ & Iran & Duodenum & Unknown & Died from sepsis \\
\hline \multicolumn{6}{|c|}{ Hamour et al (23), 1998} \\
\hline 1 & $\begin{array}{l}\text { Weight loss, polyarthralgia, } \\
\text { painless skin lesions }\end{array}$ & France, Spain & Skin, bone marrow & $\begin{array}{l}\text { Amphotericin B, switched to liposomal } \\
\text { amphotericin B; relapsed and } \\
\text { liposomal amphotericin B triggered } \\
\text { renal toxicity; changed to sodium } \\
\text { stibogluconate, then IV pentamidine } \\
\text { every } 2 \text { weeks }\end{array}$ & $\begin{array}{l}\text { Responded, relapsed, } \\
\text { responded to second } \\
\text { course of treatment }\end{array}$ \\
\hline 2 & $\begin{array}{l}\text { Pallor, epigastric tenderness, } \\
\text { organomegaly }\end{array}$ & Fiji/Uganda & $\begin{array}{l}\text { Duodenum, bone } \\
\text { marrow }\end{array}$ & $\begin{array}{l}\text { Amphotericin B, then pentamidine } \\
\text { every } 2 \text { weeks }\end{array}$ & $\begin{array}{l}\text { Repeat bone marrow after } \\
\text { initial amphotericin B } \\
\text { revealed reduction in } \\
\text { parasitic load }\end{array}$ \\
\hline \multicolumn{6}{|l|}{ Jawhar (24), 2011} \\
\hline 1 & $\begin{array}{l}\text { Abdominal discomfort, } \\
\text { diarrhea, vomiting }\end{array}$ & Yemen & $\begin{array}{l}\text { Duodenum, rectum, } \\
\text { bone marrow }\end{array}$ & Sodium stibogluconate & Lost to follow-up \\
\hline
\end{tabular}

VL is considered to be an opportunistic infection in the context of HIV coinfection. VL increases HIV viral replication and, in turn, is more severe; atypical presentations of VL are more common when patients are coinfected with HIV (5).

We speculate that our patient may have acquired leishmaniasis earlier in life when he lived closer to the Sudanese-Ethiopian border and, subsequently, acquired HIV; however, it is not possible to confirm this hypothesis.

Atypical VL can present variably because of the variety of organ systems that can be involved (eg, the gastrointestinal, respiratory, renal or hepatic systems, among others). In the context of often quite severe immunocompromise due to HIV, the clinician should maintain a high index of suspicion for atypical VL when evaluating symptomatic individuals from areas where leishmaniasis is endemic (6). HIV-positive patients with VL have higher initial leishmaniasis treatment failure, relapse and mortality rates (7). In our patient, the lack of a rise in CD4 levels, despite suppressive antiretroviral therapy, led to consideration of this diagnosis. A recent study from Spain (8), demonstrated VL to be associated with a high level of immune activation and bacterial translocation (measured by interleukin-6, lipopolysaccharides and, especially, soluble CD14), and poor CD4 rise despite effective HAART.

\section{Treatment of VL}

VL can be treated with several agents, such as pentavalent antimonials, amphotericin B, paromomycin and miltefosine; however, the WHO now recommends liposomal amphotericin B as its first preferred regimen in several clinical situations in several geographical regions due to its lower toxicity and excellent clinical efficacy. The markedly increased rates of antimonial toxicity, which HIV-infected individuals 
experience when compared with those who are HIV negative limits this medication's use $(7,9)$.

There are other individual agents, such as paromomycin and miltefosine, the latter being the first oral agent. Drawbacks include liver or renal toxicity, cost and varying potential for resistance (2). Miltefosine is well tolerated; however, it has a lower cure rate compared with sodium stibogluconate (an antimonial), and a higher relapse rate $(7,10)$. It is only available in Canada through the Health Canada Special Access program, and the cost for a 28-day course at $100 \mathrm{mg}$ daily is $\$ 3,335.48$ (personal communication with Manitoba HIV Program pharmacist).

Unfortunately, liposomal amphotericin B is not as widely available as other agents $(6,11)$. It has been shown to be effective in treating HIV/leishmaniasis coinfection, with an initial cure rate of $59.5 \%$; however, less so in HIV-positive leishmaniasis relapse scenarios (38\%) (9).

Combination therapy with $>1$ drug with antileishmanial activity is being considered, given the high failure and relapse rates with monotherapy $(9,12-14)$. All of the above-mentioned drugs are believed to act on different targets (15). A retrospective review of the use of liposomal amphotericin B $(30 \mathrm{mg} / \mathrm{kg})$, along with 28 days of miltefosine in an HIV-positive population in Ethiopia, produced an initial cure rate of $87 \%$ in HIV-positive leishmaniasis relapse coinfections $(7,16)$. The additive effect of miltefosine may be the result of immunomodulation with boosting of cell-mediated immunity, as illustrated in an experimental model (17).

The hope is that with combination therapy, treatment duration may be shortened, reducing the risk for developing adverse effects, improving compliance and reducing health care costs. Miltefosine, for example, has a very long half-life, and may be well served by being used in combination regimens to prolong and protect its utility (15). More research is needed to determine the best treatment regimen for HIV-coinfected individuals.

Because individuals coinfected with HIV have a higher risk for relapse (up to $60 \%$ at one year $[5,15]$ ), secondary prophylaxis has been considered. Risk factors for relapse include a very low CD4 count at presentation, past relapse, low body mass index and a CD4 count $<200$ cells $/ \mathrm{mm}^{3}$ (and especially $<100$ cells $/ \mathrm{mm}^{3}$ ) at six months posttreatment (18). Our patient's CD4 count was 71 cells $/ \mathrm{mm}^{3}$ six months after his initial treatment, and 158 cells $/ \mathrm{mm}^{3}$ after the second. An alternative approach is to monitor for serum leishmaniasis DNA PCR, and treat relapses should the PCR become detectable (3).

For individuals diagnosed with leishmaniasis not already receiving HAART, there is no need to delay starting because adverse immune reactions are uncommon and not severe (7). In vitro studies of HIV protease inhibitors have suggested that some may have both direct and indirect antileishmanial effects; however, more research is required to confirm that there is a clinical benefit (2).

\section{Gastrointestinal involvement}

Atypical VL is more common in those with HIV coinfection, and can involve systems such as the respiratory, renal, hepatic or gastrointestinal, among others. Gastrointestinal involvement has been extensively reported in the context of $L$ infantum, but appears to be

\section{REFERENCES}

1. AU Russo R, Nigro LC, Minniti S, et al. Visceral leishmaniasis in HIV infected patients: Treatment with high dose liposomal amphotericin B (AmBisome). J Infect 1996;32:133

2. van Griensven J, Diro E, Lopez-Velez R, et al. HIV-1 protease inhibitors for treatment of visceral leishmaniasis in HIV-co-infected individuals. Lancet Infect Dis 2013;13:251-9.

3. van Griensven J, Carrillo E, Lopez-Velez R, Lynen L, Moreno J. Leishmaniasis in immunosuppressed individuals. Clin Microbiol Infect 2014;20:286-99.

4. Abass E, Kang C, Martinkovic F, et al. Heterogeneity of Leishmania donovani parasites complicates diagnosis of visceral leishmaniasis: Comparison of different serological tests in three endemic regions. PloS one 2015;10:e0116408

5. van Griensven J, Diro E. Visceral leishmaniasis. Infect Dis Clin North Am 2012;26:309-22. relatively common among individuals coinfected with HIV from Ethiopia (6,11). Our client experienced gastrointestinal tract symptoms, which predated his diagnosis by several years, and biopsies confirmed leishmaniasis infection at esophageal, gastric and duodenal sites.

After both treatment courses, his gastrointestinal symptoms resolved and, to date, it appears that the second course of therapy, which combined IV amphotericin B with miltefosine, has been successful. Secondary prophylaxis has not been administered, and the decision was made to follow his leishmaniasis DNA PCR to quickly identify a relapse, should one occur. Fortunately, at last follow-up nine months after he completed treatment, he remained negative.

While the gastrointestinal mucosal appearance may be abnormal, in some situations it may appear unremarkable or suggest an alternate diagnosis. In one article, the diagnosis was made in two individuals based solely on examination of the biopsy material (19), and a negative bone marrow aspirate does not always rule out VL (3). For HIV-positive individuals who are from an area where Leishmania is endemic and present with gastrointestinal symptoms, preserving a high index of suspicion for the disease would allow for a greater chance of detection and, therefore, treatment of a potentially curable opportunistic infection.

A review of case reports, which featured gastrointestinal involvement in HIV-positive individuals with VL is summarized in Table 1.

\section{CONCLUSION}

Atypical presentations of VL are not uncommon in the HIV-positive population. HIV-coinfected individuals are at risk for atypical site involvement, such as the gastrointestinal tract, and are also at increased risk for relapse after treatment. Gastrointestinal involvement appears to be common among HIV-coinfected individuals from Ethiopia.

Our patient experienced some of the common presenting clinical features of VL (organomegaly and pancytopenia), along with gastrointestinal symptoms but, significantly, without fever. He relapsed after his first course of therapy but, to date, appears to have avoided a relapse after undergoing combination therapy with amphotericin B and miltefosine.

It is important to be aware that leishmaniasis should be included in the differential diagnosis when investigating symptomatic HIV individuals who reside or resided, in leishmaniasis-endemic regions, to ensure that this curable, but otherwise lethal, infection is treated.

While relapse rates are higher than in those who are HIV negative, and there is a need for research to clarify the answers to outstanding questions (such as the role of combination therapy, relapse prevention and appropriate post-treatment monitoring), one of the first challenges is to ensure that individuals with leishmaniasis are diagnosed. This is made more difficult by atypical presentations, such as that observed in our patient, and is why we believed it important to share his experience.

DISCLOSURES: The authors have no financial relationships or conflicts of interest to declare.

6. Diro E, van Griensven J, Mohammed R, et al. Atypical manifestations of visceral leishmaniasis in patients with HIV in north Ethiopia: A gap in guidelines for the management of opportunistic infections in resource poor settings. Lancet Infect Dis 2015;15:122-9.

7. Jarvis JN, Lockwood DN. Clinical aspects of visceral leishmaniasis in HIV infection. Curr Opin Infect Dis 2013;26:1-9.

8. Casado J, Abad-Fernandez M, Moreno S, et al. Visceral leishmaniasis as an independent cause of high immune activation, T-cell senescence, and lack of immune recovery in virologically suppressed HIV-1 coinfected patients. HIV Med 2015;16:240-8.

9. Ritmeijer K, ter Horst R, Chane S, et al. Limited effectiveness of high-dose liposomal amphotericin B (AmBisome) for treatment of visceral leishmaniasis in an Ethiopian population with high HIV prevalence. Clin Infect Dis 2011;53:e152-8. 
10. Ostyn B, Hasker E, Dorlo TP, et al. Failure of miltefosine treatment for visceral leishmaniasis in children and men in South-East Asia. PLoS One 2014;9:e100220.

11. Diro E, Lynen L, Ritmeijer K, Boelaert M, Hailu A, van Griensven J. Visceral leishmaniasis and HIV coinfection in East Africa. PLoS Negl Trop Dis 2014;8:e2869.

12. Cota GF, de Sousa MR, Fereguetti TO, Rabello A. Efficacy of anti-Leishmania therapy in visceral leishmaniasis among HIV infected patients: A systematic review with indirect comparison. PLoS Negl Trop Dis 2013;7:e2195.

13. Sundar S, Chakravarty J. An update on pharmacotherapy for leishmaniasis. Expert Opin Pharmacother 2015;16:237-52.

14. Kumar VD, Verma PR, Singh SK. New insights into the diagnosis and chemotheraphy for visceral leishmaniasis. Curr Drug Deliv 2014;11:200-13.

15. van Griensven J, Balasegaram M, Meheus F, Alvar J, Lynen L, Boelaert M. Combination therapy for visceral leishmaniasis. Lancet Infect Dis 2010;10:184-94.

16. van Griensven J, Boelaert M. Combination therapy for visceral leishmaniasis. Lancet 2011;377:443-4.

17. Shivahare R, Vishwakarma P, Parmar N, et al. Combination of liposomal $\mathrm{CpG}$ oligodeoxynucleotide 2006 and miltefosine induces strong cell-mediated immunity during experimental visceral leishmaniasis. PLoS One 2014;9:e94596.

18. Cota GF, de Sousa MR, Rabello A. Predictors of visceral leishmaniasis relapse in HIV-infected patients: A systematic review. PLoS Negl Trop Dis 2011;5:e1153.

19. Alonso MJ, Munoz E, Picazo A, et al. Duodenal leishmaniasis diagnosed by biopsy in two HIV-positive patients. Pathol Res Prac 1997;193:43-7.

20. Diro E, Lynen L, Gebregziabiher B, et al. Clinical aspects of paediatric visceral leishmaniasis in north-west Ethiopia. Trop Med Int Health 2015;20:8-16.

21. Canet JJ, Julia J, Martinez-Lacasa J, Garau J. Clinical microbiological case: Esophageal lesion in an AIDS patient. Clin Microbiol Infect 2003;9:421,463-6

22. Molaei M, Minakari M, Pejhan S, Mashayekhi R, Modaress Fatthi AR, Zali MR. Intestinal leishmaniasis in acquired immunodeficiency syndrome. Iran Red Crescent Med J 2011;13:348-51.

23. Hamour AA, Skelly R, Jowitt SN, et al. Visceral leishmaniasis (Kala-azar) in two patients with HIV-1 infection: Atypical features and response to therapy. J Infect 1998;36:217-20.

24. Jawhar NM. Visceral leishmaniasis with an unusual presentation in an HIV positive patient. SQU Med J 2011;11:269-72. 


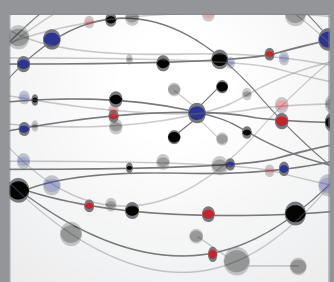

The Scientific World Journal
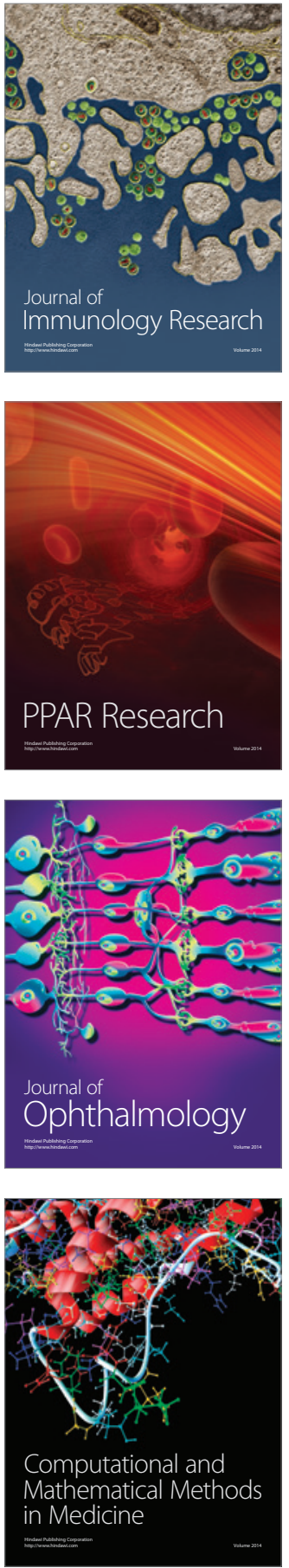

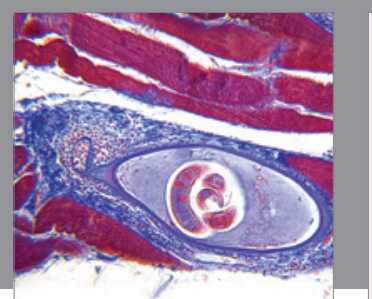

Gastroenterology Research and Practice

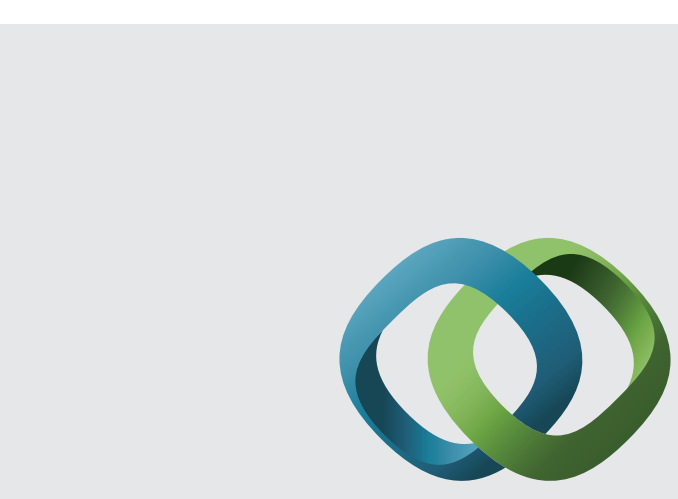

\section{Hindawi}

Submit your manuscripts at

http://www.hindawi.com
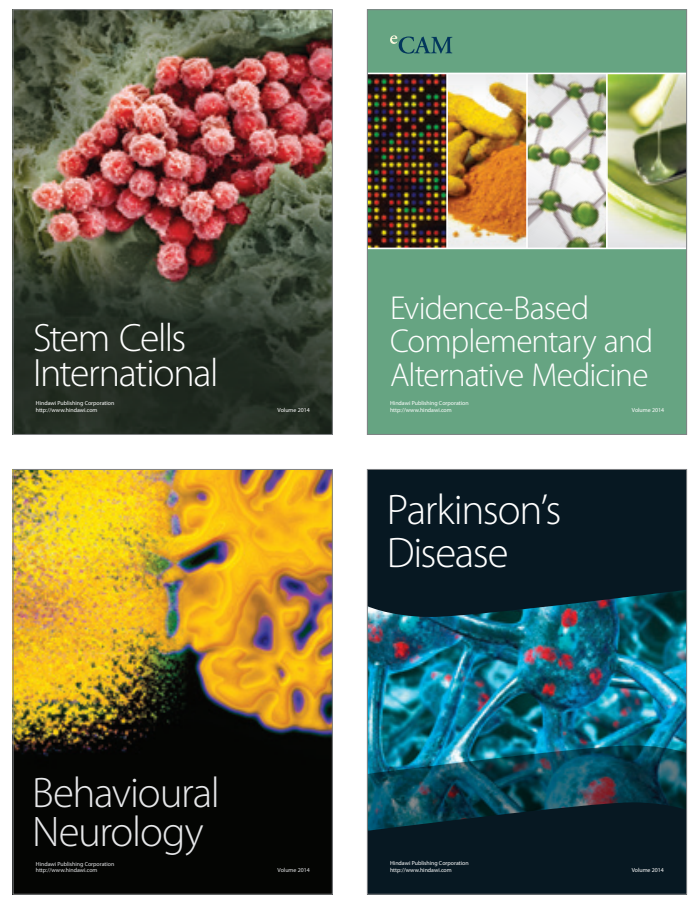
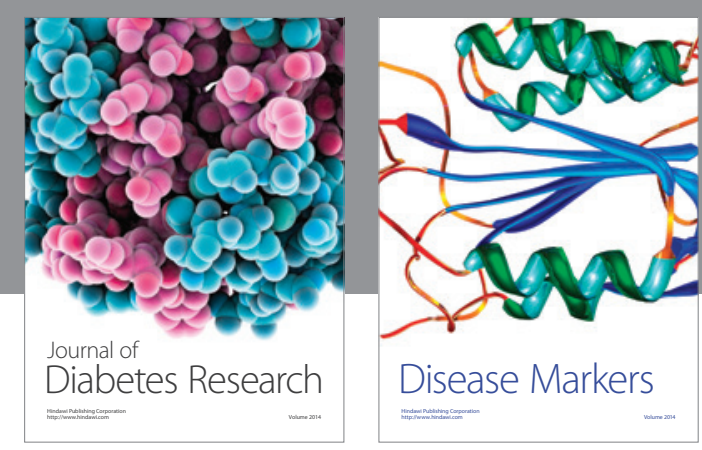

Disease Markers
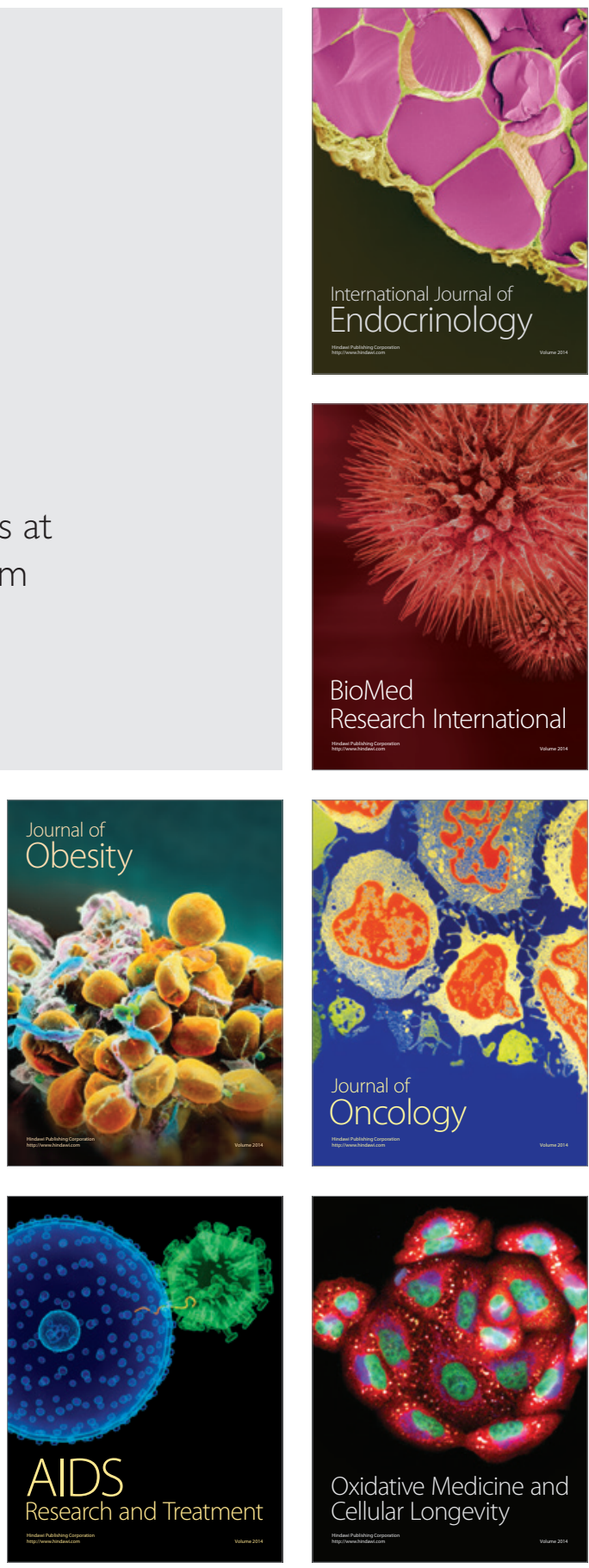